\title{
FAKTOR PENENTU KUALITAS LAYANAN STUDI PADA UNIVERSITAS ISLAM LAMONGAN
}

\author{
Puguh Cahyono \\ Fakultas Ekonomi Universitas Islam Lamongan \\ puguhcahyono@unisla.ac.id \\ Dhita Dhora Damayanti \\ Fakultas Ekonomi Universitas Islam Lamongan \\ dhitadhora@unisla.ac.id
}

\begin{abstract}
Abstrak
Sebagai salah satu institusi perguruan tinggi di Kabupaten Lamongan, Universitas Islam Lamongan (Unisla) dituntut memberikan pelayanan yang terbaik. Hal ini dikarenakan Unisla merupakan sebuah perusahaan yang bergerak dibidang jasa pendidikan tinggi dimana kualitas layanan dari perguruan tinggi tidak hanya diatur dalam regulasi pemerintah namun juga tuntutan agar dapat bersaing dengan pendidikan tinggi lainnya dalam skala yang luas. Penelitian ini bertujuan untuk mengetahui lebih dalam mengenai faktorfaktor yang menentukan dimensi kualitas layanan dari Universitas Islam Lamongan dari prespektif mahasiswa dimana nantinya hasil dari penelitian ini akan digunakan sebagai dasar untuk perbaikan dan jaminan mutu Unisla. Penelitian ini dilakukan dengan mendistribusikan kuesioner yang respondennya adalah mahasiswa aktif Unisla dari seluruh fakultas yaitu fakultas agama islam, ekonomi, teknik, hukum, perikanan, peternakan, keguruan dan ilmu pendidikan serta kebidanan. Adapun kuesioner yang disitribusikan pada 100 responden dengan metode pengambilan sampel random sampling yang kemudian diolah dan dianalisis menggunakan analisa statistik yaitu analisis faktor. Hasil penelitian menunjukkan bahwa dimensi kualitas layanan Unisla dibentuk oleh lima faktor, yaitu Faktor Nilai-nilai dosen, Citra, Sikap Staf, Keandalan Staf dan Aksesbilitas.
\end{abstract}

Kata Kunci: Kualitas Layanan,Dimensi Kualitas Layanan, Faktor Kualitas Layanan, Pendidikan Tinggi

\section{Pendahuluan}

Sebuah institusi pendidikan tinggi terutama perguruan tinggi swasta (PTS) di Indonesia memang sangat mudah ditemui. Namun dengan banyaknya PTS ini menyebabkan persaingan antar satu PTS dengan PTS lainnya dalam memperoleh mahasiswa. Dalam hal ini artinya PTS perlu meyakinkan, memberikan jaminan dan menumbuhkan rasa percaya pada mahasiswa maupun calon mahasiswanya.

Hal ini sangat berguna untuk meningkatkan kepuasan dan loyalitas nasabah pada mahasiswa.Persaingan ini juga terjadi di PTS yang ada di Lamongan, 
salah satunya adalah pada Universitas Islam Lamongan (Unisla).

Sebagai PTS yang ada di kota kecil dan memiliki cukup banyak pesaing, Unisla perlu bersaing dari sisi pelayanan agar mampu meraih pasar. Salah satu hal yang dapat dilakukan oleh adalah memberikan kualitas layanan yang prima bagi mahasiswa. Hal ini menjadi pertimbangan mengingat kualitas layanan bagi perusahaan yang menjual jasa seperti Unisla merupakan hal yang utama.

Melalui fenomena tersebut, penulis tertarik untuk melakukan pengujian terhadap faktor-faktor apa saja yang menjadi penentu kualitas layanan di Universitas Islam Lamongan.

\section{Rerangka Teoritis dan Hipotesis Kualitas Layanan}

Kualitas adalah sejauh mana produk atau jasa memenuhi spesifikasi spesifikasinya (Rambat, 2001). menurut (Smith, 1998) kualitas layanan adalah terpenuhinya kebutuhan dan ekspektasi dari konsumen. Parasuraman et.al (1988) mendefinisikan kualitas layanan sebagai sebuah bentuk penilaian yang timbul dari konsumen atas tingkat layanan yang diterima oleh konsumen tersebut (perceived service) terhadap tingkat layanan yang diharapkan oleh konsumen (expected service). Selain itu, Kualitas layanan telah diturunkan dari bidang pemasaran yang menilai interaksi manusia anntara bisnis dan pelanggannya yang mana hal ini berfokus pada hubungan antara harapan pelanggan atas layanan dan persepsi mereka tentang kualitas layanan yang diberikan. (Gronroos, 2007).

\section{Dimensi Kualitas Layanan}

Model ini berkaitan erat dengan model kepuasan. Dalam model Servqual, kualitas layanan didefinisikan sebagai penilaian atau sikap global yang berkenaan dengan superioritas suatu jasa (Parasuraman, et al,1985). Definisi pada tiga landasan konseptual utama, yakni:

1. Kualitas jasa lebih sukar dievaluasi konsumen daripada kualitas barang.
2. Persepsi terhadap kualitas jasa merupakan hasil dari perbandingan antara harapan pelanggan dengan kinerja aktual jasa.

3. Evaluasi kualitas tidak hanya dilakukan atas hasil jasa, tetapi juga mencakup evaluasi terhadap proses penyampaian jasa.

Dimensi kualitas layanan dibangun atas adanya perbandingan dua faktor utama, yaitu persepsi pelanggan atas layanan nyata yang mereka terima (Perceived Service) dengan layanan yang sesungguhnya yang diharapkan atau diinginkan (Expected Service). Jika kenyataan lebih dari yang diharapkan, maka layanan dapat dikatakan bermutu, sedangkan jika kenyataan kurang dari yang diharapkan, maka layanan dikatakan tidak bermutu.

Apabila kenyataan sama dengan harapan maka layanan tersebut memuaskan. Dimensi kualitas layanan yang di rumuskan oleh Parasuraman, et al. (1985, 1988) biasa dikenal dengan dmensi SERVQUAL yaitu :

1. Daya tanggap, yaitu kemampuan untuk menolong pelanggan dari ketersediaan untuk melayani pelanggan yang baik.

2. Keandalan, yaitu kemampuan untuk melakukan pelayanan sesuai yang dijadikan dengan segera,akurat dan memuaskan.

3. Empati, yaitu rasa peduli untuk memberikan perhatian secara individual kepada pelanggan, memahami kebutuhan pelanggan serta kemudahan untuk dihubungi.

4. Jaminan, yaitu pengetahuan, kesopanan petugas serta sifatnya yang dapat dipercaya sehingga pelanggan terbebas dari resiko.

5. Bukti fisik, yaitu meliputi fasilitas fisik, perlengkapan karyawan dan sarana komunikasi.

Salah satu faktor yang menentukan kepuasan pelanggan mengenai kualitas jasa yang berfokus pada lima dimensi jasa. Kepuasan pelanggan, selain dipengaruhi 
oleh persepsi kualitas jasa juga ditentukan oleh kualitas produk, harga dan faktorfaktor yang bersifat pribadi serta yang bersifat situasi sesaat.

Pengukuran kualitas layanan selain menggunakan SERVQUAL juga dapat diukur dengan SERVPERF yang dikembangkan oleh Cronin \& Taylor (1994). Berbeda dengan SERVQUAL, SERFPERF lebih cenderung pada performancebased untuk mengukur kualitas layanan berdasarkan komponen persepsi. Semakin berkembangnya zaman, konsep baru tentang kualitas layanan muncul, yaitu HEdPERF. HEdPERF dikembangkan dengan membandingkan 41 set item yang didalamnya tidak hanya mempertimbangkan komponen akademik tetapi juga semua aspek dari lingkungan pelayanan yang dirasakan oleh mahasiswa. (Firdaus, 2006).

Terdapat lima dimensi dari kualitas layanan, yaitu: a. Aspek non-akademik. Item yang penting yang dapat mendukung para mahasiswa untuk memenuhi kewajiban belajarnya dan menghubungkan tugas yang dibawa oleh staf non-akademik b. Aspek akademik, yaitu kewajiban akademik c. Reputasi. Pentingnya Perguruan Tinggi dalam mengembangkan image professional d. Akses. Termasuk hal yang berhubungan dengan kemampuan untuk dicapai, kemudahan untuk dihubungi, ketersediaan dan kemudahan e. Program yang ada. Penawaran program akademik/spesialisasi

\section{Metode Penelitian \\ Rancangan Penelitian}

Rancangan penelitian yang digunakan pada penelitian ini didasari oleh beberapa klasifikasi (Cooper \& Schindler, 2008 : 142) yakni penelitian eksploratif dan eksplanatif karena disamping melakukan eksplorasi juga bertujuan menjelaskan hubungan kausal antar variabel melalui pengujian hipotesis, penelitian survei dengan menggunakan kuesioner sebagai alat pengumpulan data, penelitian cross sectional, penelitian primer dimana penelitian menggunakan data primer dan penelitian statistical study dimana penelitian menggunakan pengujian statistik dalam analisis data untuk memecahkan masalah penelitian.

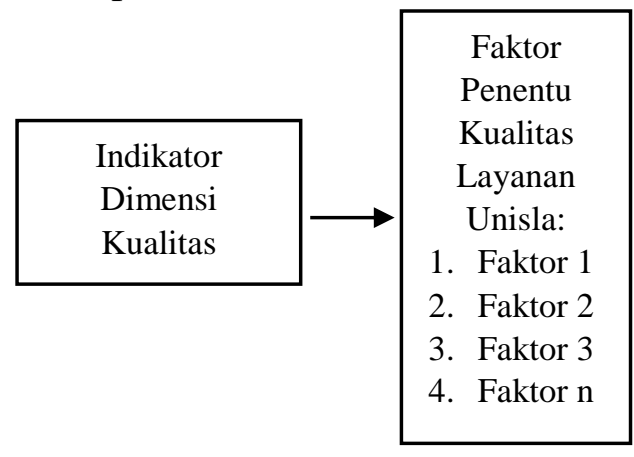

\section{Analisa Faktor}

\section{Gambar 1}

Rerangka Penelitian

Faktor yang terbentuk setelah dilakukan pengujian adalah sebanyak lima faktor dimana kelima faktor tersebut memiliki nilai eigenvalue lebih dari 1 .

\section{Tabel 3}

KMO dan Bartlett's Test

\begin{tabular}{|l|l|r|}
\hline \multicolumn{2}{|l|}{} & Nilai \\
\hline $\begin{array}{l}\text { Kaiser-Meyer-Olkin Measure of } \\
\text { Sampling Adequacy. }\end{array}$ & 0.825 \\
\hline $\begin{array}{l}\text { Bartlett's Test of } \\
\text { Sphericity }\end{array}$ & $\begin{array}{l}\text { Approx. Chi- } \\
\text { Square }\end{array}$ & 1.8873 \\
\cline { 2 - 3 } & df & 325 \\
\cline { 2 - 3 } & Sig. & .000 \\
\hline
\end{tabular}

Berikut merupakan faktor pembentuk kualitas layanan:

1. Nilai-nilai dosen. Faktor ini merupakan faktor utama yang membentuk kualitas layanan di Unisla. Dimana faktor ini merepresentasikan tenaga pengajar dari Unisla. Nilai-nilai ini meliputi pengetahuan dosen, sikap dosen terhadap mahasiswa hingga kemampuan dosen memahami nilainilai akademik yanga ada di Unisla

2. Citra. Faktor ini merupakan salah satu faktor yang dibentuk dari bagaimana Program Studi yang ada di Unisla memberikan kinerja yang nyata untuk para mahasiswanya. Hal ini akan tercermin pada beragam program yang dibuat oleh program studi, kualitas 
program hingga keterserapan lulusan di dunia kerja.

3. Sikap staf.Faktor ini adalah faktor kualitas layanan yang menggambarkan kemampuan staf administrasi dalam melakukan pelayanan terutama terhadap mahasiswa. Misalnya sikap staf terhadap mahasiswa, keinginan untuk membantu, hingga pengetahuan staf tentang tata administrasi.

4. Keandalan.Faktor ini merepresentasikan etos kerja Unisla baik staf, manajemen maupun tenaga pengajar. Misalnya, kecepatan layanan dari staf administrasi hingga kemampuan dalam menjaga kerahasiaan informasi.

5. Komunikasi adalah faktor yang berkaitan dengan kemudahan dalam akses komunikasi dengan mahasiswa, respon yang baik terhadap mahasiswa hingga dukungan kampus terhadap serikat mahasiswa.

\section{Kesimpulan, Implikasi, Keterbatasan dan Saran}

Berdasarkan hasil pengolahan data menggunakan analisa faktor maka dapat disimpulkan bahwa terdapat lima faktor pembentuk kualitas layanan Universitas Islam Lamongan yaitu: Nilai-nilai dosen, Citra, Sikap Staf, Kendalan dan Aksesbilitas.

Adapun keterbatasan yang ada dalam penelitian ini yaitu (1) Adanya data dari responden yang tidak bisa dimasukkan dalam penelitian karena tidak masuk dalam kriteria pengambilan sampel (2) Kurang meratanya dalam mendapatkan responden dari berbagai fakultas yang menjadi obyek penelitian

Dengan adanya hasil dan keterbatasan dalam penelitian ini, maka saran yang dapat diberikan kepada Unisla yaitu (1) Unisla sebagai perguruan tinggi yang menjual jasa pelayanan dan pengajaran diharapkan untuk lebih meningkatkan sumber daya tenaga pengajarnya. Hal ini bisa dari sisi kualitas pengajar, pengetahun maupun sikap dosen terhadap mahasiswa.
Untuk meningkatkan hal-hal tersebut bisa dengan cara memberikan pelatihan untuk mengupdate pengetahuan dan kemampuan dosen. (2) Dari faktor Citra, Unisla bisa melakukan inovasi untuk berbagai macam program belajar, meningkatkan kualitas program-program yang sudah ada baik program studinya maupun program kerjanya sehingga mampu memberikan reputasi yang baik sehingga memudahkan lulusannya terserap dalam dunia kerja. (3) Berdasarkan faktor sikap staf, hendaknya pihak Unislabisa memberikan pelayanan yang prima terutama staf administrasi. Misalnya dengan meberikan pelayanan yang cepat, bersikap baik terhadap mahasiswa hingga memiliki pengetahuan yang baik mengenai tentang tata administrasi. (4) Faktor keandalan adalah kemampuan dari Unisla untuk melakukan pelayanan sesuai yang dijadikan dengan segera, akurat dan memuaskan. Oleh karena itu hendaknya memiliki etos kerja yang tinggi, kecepatan pelayanan dan memiliki program yang berkualitas.(5)Aksesbilitas adalah faktor dimana mahasiswa memiliki kemudahan untuk berkomunikasi dengan pihak Unisla baik dalam hal menyampaikan pendapat maupun dalam pencairan informasi. Oleh karena itu hendaknya Unisla meningkatkan atau memperbaiki media komunikasi yang bisa memberikan kemudahan bagi kedua belah pihak.

Bagi peneliti selanjutnya Bagi peneliti selanjutnya, disarankan untuk menambah variabel yang berkaitan dengan kepuasan dan loyalitas misalnya word of mouth marketing. Selain itu disarankan untuk menggali lebih banyak faktor pembentuk kualitas layanan dari beberapa sektor.

\section{Daftar Rujukan}

Brocado, Ana. (2009). "Comparing Alternative Instrument To Measure Service Quality In Higher Educatio", Quality Assurance in Education, Vol. 17 No.2 pp 174190 
Cooper, Donald $\mathrm{R}$ dan Pamela S. Schindler. 2008.Business Research Methods. Fifth Edition. New York. Richard D Irwin Inc.

Dewi Ayu Wulandari dan Tatik Suryani. 2017. Service Quality And The Impact On Student's Satisfaction Loyalty To Master Of Management Program In Surabaya. Journal of Research in Economics and Management. Vol 17 (1).

Dhita Dhora Damayanti. 2017. Faktor Penentu Kualitas Layanan Perbankan Serta Pengaruhnya Terhadap Kepuasan dan Loyalitas Nasabah Perbankan di Lamongan. Jurnal Penelitian Ekonomi dan Akuntansi. Vol 2 (3): 503-517

Dhyka Bagus Permana. 2011. FaktorFaktor Penentu Kualitas Jasa Perbankan Di Surabaya (Studi Komparasi Persepsi Nasabah Dan Karyawan). Journal of Business and Banking, Vol 1 (1): 75-84.

Fandy Tjiptono, 2006.Prinsip-Prinsip Total Quality Service. Yogyakarta. PenerbitAndi.

$\begin{array}{lr}\text { Management: } & \text { 2008.Service } \\ \text { Layanan Prima. } & \text { Mowujudkan } \\ \text { Penerbit Andi. } & \end{array}$

Gronroos, C. 2007. A service quality model and marketing implications. European Journal of Marketing, 18(4), 36-44.

Hermawan Kartajaya, Ardhi Ridwansyah. 2011.Service with Character: 18 Prinsip Keberhasilan Layanan di Era Horizontal dalam Menciptakan Loyalitas dan Rekomendasi Pelanggan.Jakarta. Penerbit Gramedia Pustaka Utama.

Imam Ghozali. 2014. Structural Equation Modeling :MetodeAlternatifdengan Partial Least Squares (PLS). Semarang :UniversitasDiponegoro ImamGhozali\&HengkyLatan.2014. Partial Least Squares :Konsep,
MetodedanAplikasi. Semarang :UniversitasDiponegoro

Johnson, M.D. \&Gustafsson, A. \&Andreassen, T.W. \&Lervik, L. \& Cha.2001. The evolution and future of nation customer satisfaction index models. Journal of Economic Psychology, 22(2), 217-245.

Kotler, Philip dan Keller, Kevin Lane. 2008.Manajemen

Pemasaran. Jakarta. Penerbit Erlangga.

Larson, S. \& Susanna, H. 2004.Managing customer loyalty in the automobile industry. Department of Business Administration and Social science.

Lau, Mei Mei, Cheung, Ronnie, Lam, Aris Y. C., Chu, Yuen Ting. 2013. Measuring Service Quality in the Banking Industry: A Hong Kong Based Study. Contemporary Management Research, Vol 9 (3): 263-282.

Majalah Infobank-Biro Riset Info Bank periode 2010 sampaidengan 2014. "Indonesian Bank Loyality Index (ILBI)". EdisiJanuari 2014. Jakarta.

Mistry, Snehalkumar H. 2013. Measuring Customer Satisfaction In banking sector: with Special Reference to Bank of Surat City.Asia Pacific Journal of Marketing \& management Review, Vol 2 (7): 132.

Neal, W. D. 1998. Satisfaction be damned, value drives loyalty. Diambil kembali dari http://www.sdrconsulting.com/article4.html

OJK. (t.thn.). Diambil kembali dari ojk.go.id:

http://www.ojk.go.id/edukasiperbankan.

Parasuraman, A., Berry, L. L. \& Zeithaml, V. A. 1985. A conceptual model of service quality and its implications for future research.Journal of Marketing Research, Vol 49 (4): 41-48. 
Parasuraman, A, Valarie A Zeithaml dan Leonard

Berry.1988.SERVQUAL:A

multiple-item scale for measuring consumer perceptions of service quality.Journal of Retailing, Vol 64:pp 12-40.

RambatLupiyoadi, R. 2001. Manajemen

Pemasaran Jasa: Teori dan Praktek. Jakarta: Salemba Emban Patrio.

Sellappan, R., Devi, P. Praba, \& Prabakar, C.R. 2013. Sevice Quality in Retailing, Banking and Insurance: A Comparative Study.Sona Global Magement Review, Vol 7(4): 40.

Smith, S. 1998. How to create a plan to deliver great customer service. New York, NY: AMACOM.

Sugiyono. 2011. Metode Penelitian Kuantitatif, Kualitatif dan $R \& D$. Bandung: Penerbit Alfabeta. 
Rotated Component Matrix ${ }^{a}$

\begin{tabular}{|c|c|c|c|c|c|}
\hline & \multicolumn{5}{|c|}{ Component } \\
\hline & 1 & 2 & 3 & 4 & 5 \\
\hline Pengetahuan Dosen Luas & .895 & & & & \\
\hline Sikap Dosen Baik & .859 & & & & \\
\hline Dosen memahami kebutuhan mahasiswa & .820 & & & & \\
\hline Komunikasi Dosen baik & .792 & & & & \\
\hline Keinginan dosen membantu mahasiswa & .788 & & & & \\
\hline Reputasi program studi & .756 & & & & \\
\hline Dosen paham nilai-nilai akademik & .745 & & & & \\
\hline Fasilitas dan peralatan kampus & .523 & & & & \\
\hline Keberagaman program kampus & & .777 & & & \\
\hline Kualitas program kampus & & .764 & & & \\
\hline Lokasi kampus & & .755 & & & \\
\hline Ukuran kelas kampus & & .741 & & & \\
\hline Sarana komunikasi kampus & & .567 & & & \\
\hline Keterserapan lulusan & & .544 & & & \\
\hline Sikap staf administrasi & & & .819 & & \\
\hline Kemauan staf administrasi untuk mendampingi mahasiswa & & & .720 & & \\
\hline Keinginan staf administrasi untuk membantu & & & .659 & & \\
\hline Pengetahuan staf Tata administrasi & & & .625 & & \\
\hline Etos kerja staf administrasi & & & & .837 & \\
\hline Kemampuan dalam menjaga informasi & & & & .750 & \\
\hline Program studi mampu bersaing & & & & .729 & \\
\hline Pelayanan cepat & & & & .632 & \\
\hline Dukungan pada serikat mahasiswa & & & & & .764 \\
\hline Kemudahan akses komunikasi & & & & & .653 \\
\hline Umpan balik kampus & & & & & 621 \\
\hline Perlakuan terhadap mahasiswa & & & & & .571 \\
\hline
\end{tabular}

Extraction Method: Principal Component Analysis.

Rotation Method: Varimax with Kaiser Normalization.

a. Rotation converged in 8 iterations. 